\title{
The preservation of genetic resources of the vine requires cohabitation between institutional clonal selection, mass selection and private clonal selection
}

\author{
Jean-Philippe Roby ${ }^{1,2, a}$, Cornelis van Leeuwen ${ }^{1,2}$, Elsa Gonçalves ${ }^{3,4}$, Antonio Graça ${ }^{4}$ and Antero Martins ${ }^{3,4}$ \\ ${ }^{1}$ Univ. Bordeaux, ISVV, Ecophysiology and functional genomics of grapevines, UMR 1287, 33140 Villenave d'Ornon, \\ France \\ 2 Bordeaux Sciences Agro, ISVV, Ecophysiology and functional genomics of grapevines, UMR 1287, \\ 33140 Villenave d'Ornon, France \\ ${ }^{3}$ Instituto Superior de Agronomia, Lisbon University. Tapada da Ajuda, 1349-017 Lisboa, Portugal \\ ${ }^{4}$ Associação Portuguesa para a Diversidade da Videira (PORVID). Tapada da Ajudag, 1349-017 Lisboa, Portugal
}

\begin{abstract}
Clonal selection allows control of virus diseases and selection of genotypes on agronomic, viticultural or enological criteria. Clonal selection has the major drawback that it impoverishes genetic diversity and exposes growers to environmental instability of clones (genotype $\mathrm{X}$ environment interaction). Clonal selection has become the almost unique way of propagating plant material for vineyards, hence threatening the genetic diversity of the grapevine. For major grapevine varieties, some genetic diversity is maintained in institutional collections. However, this way of conservation is insufficiently developed, it is expensive and remains fragile. A cost effective way to preserve intra-varietal diversity is to maintain a limited proportion of mass selection in vine propagation. Private clonal selection can also contribute, in a more limited way, in maintaining genetic resources. Another approach to carry out conservation and selection of grapevine is the methodology followed in Portugal. This strategy is exemplified with the conservation/selection of an ancient Portuguese variety. The work begins with the "ex situ" conservation of a representative sample of the intravarietal diversity of the variety, which, in practice, corresponds to a large field trial with hundreds of clones under an experimental design suitable for reducing random variation of quantitative traits. From evaluating those traits (yield and must quality traits), the intravarietal diversity is quantified and the range of the predicted genotypic effects for each of those traits is analyzed. Different mass selections (polyclonal selections) are carried out for distribution and planting of new vineyards. These different mass selections provide high economic gains and also the preservation of diversity in a complementary manner to that which started the work on-farm conservation.
\end{abstract}

\section{Introduction}

Most of vines cultivated for wine making belong to the species Vitis vinifera. Each ancient variety is made out of a population of individuals who are not strictly identical on the genetic level. Hence, there is a diversity inside grape vine varieties for characteristics such as fertility, berry size or their capacity to accumulate sugar during the ripening period. Starting from a specific vine it is possible to obtain by successive propagation of the buds a great number of individuals which are strictly identical from a genetic point of view. In biology, a group of individuals having the same genome is called a "clone". From the 1960's the purpose of clonal selection was to implement the multiplication of vines having a certain number of preset characteristics (virus free, sufficiently productive, producing grapes with high sugar levels). This clonal selection made it possible to clean up and improve overall quality of the plant material sold in Europe [1]. However, the qualitative potential of the

a Corresponding author: jean-philippe .roby@agro-

bordeaux.fr certified clones varies according to grape variety. Several high quality clones were selected for Merlot, CabernetSauvignon and Sauvignon blanc, whereas the results are definitely mitigated for the Cabernet franc and Sémillon. If it is not necessary today to question the benefit of the clonal selection, it is nevertheless necessary to point out two important limits of this way of multiplication of vines. The limits should motivate professionals to consider other ways of selection to be carried out in parallel. Firstly, it is necessary to admit the qualitative limits of the clonal selection on certain grapevine variety, like Cabernet franc and Sémillon, but also the great majority of secondary varieties (Petit Verdot, Carmenère, Cot or Malbec in Bordeaux region...) [2]. Secondly, by choosing as single way of improvement of plant material the clonal selection, professionals impoverish in a dramatic way the genetic diversity which exists inside grapevine varieties.

This impoverishment cancels in fact any possibility of selecting new clones in the future. This established fact is particularly serious as the needs for the wine growers vary over time. In the 1970's producers needed 
productive clones, and grapes with high sugar levels. Today a high level of production is not any more required but the growers would like to have clones more resistant to diseases [3]. Perhaps tomorrow, if global warming is confirmed, producers will need later ripening clones, or producing grapes with moderate sugar levels. It will be more and more necessary, in order to be able to select clones answering these new criteria, to have genetic resources which allow such selections. Institutional collections exist to preserve genetic resources. These germplasm conservatories are useful but they cannot, alone, guarantee the preservation of the whole of genetic resources of the grapevine. Genetic resources can be preserved effectively and at less expensive level in the vineyard of wine growers.

However, genetic conservation and selection represent a very complex problem that requires different and complementary solutions depending on different contexts of wine and vine growing. Therefore, a different approach to carry out conservation and selection of grapevine is followed in Portugal. It is mainly focused on understanding intravarietal diversity within ancient varieties, that is, knowing how much diversity exists within each ancient variety, in which regions it is concentrated, how it should be conserved and explored through selection using the most powerful scientific methods. This approach is supported by an association that brings together universities, companies and organizations representing the wine industry (PORVID). The methodology develops over three cycles [4-6]: 1) sampling variability in different regions where the variety is grown (hundreds of mother plants in ancient vineyards); 2) planting a large field trial with sampled plants (100 to 400, each one vegetatively propagated originating a clone) with the objectives of conservation, quantification of the genetic variability of agronomic and qualitative traits and mass selection of a group of clones for immediate use and intermediate selection of clones to enter cycle 3 ; 3) planting multienvironmental trials with clones selected from cycle 2 focusing on evaluation of environmental stability (low genotype by environment interaction) and quality of wine. This paper covers the quantification of genetic diversity and mass selection of clones within ancient variety "Arinto" (cycles 1 and 2 as referred above, that is, ex situ conservation and mass selection only).

This paper is organized in two main sections: I) the strategy particularly applicable to the French context; II) the strategy currently applied in Portugal.

\section{1) Classic tools to preserve biodiversity (example of the French approach)}

\section{History of clonal selection}

The vine can be infected by numerous viruses. Some of them negatively affect the yield and/or the quality of the wines produced. However the vine is multiplied by vegetative reproduction: a new young vine is produced from a bud taken on a mother vine. A drawback of this way of propagation is the multiplication of the viruses or associated diseases. If the mother plant is infected by a virus, the vine produced by grafting will also be infected.
In the 1960's researchers started to test vines to check the absence of viruses before carrying out their multiplication. By multiplying healthy vines a great number of times by successive propagation by grafting, they obtained pure lines (genetically homogeneous) and virus free clones. In a second time, they started to introduce into this clonal selection criteria concerning different characteristics, such as yield and the capacity of the vines to produce grapes with high sugar levels, then more complex criteria like phenolic compound content of the grape or the quality of the produced wines [7]. Because of the benefit of this way of selection in reducing the impact of virus diseases, this way of selection has been quickly promoted by the organizations in control of the wine industry as the quasi unique way of selecting and propagating of grapevine plant material. Multiplication of an extremely limited number of genotypes for each cultivar resulted in a fast erosion of the genetic resources. This phenomenon becomes particularly alarming today when the wine growers are about to rip out the last vines planted before the clonal selection, i.e. planted before 1960 .

\section{Preservation of the genetic resources}

In order to preserve the genetic diversity of grape varieties, institutional germplasm conservatories were created. They are certainly useful, but it is not reasonable to count only on these conservatories for the preservation of the genetic resources of vines. Their surfaces and their numbers are insufficient to take into account the wide genetic diversity of the vine. They depend on public fundings and thus subject to possible budget cuts. By gathering the genetic resources in a small number of sites, one increases the risk of accidents: climatic catastrophes, diseases, budget cuts.... To show how fragile they are, one can quote the case of Vassal estate in France, which gathers the greatest number vine genotypes in the world (INRA, 25 ha, 7,500 genotypes, 2,600 Vitis vinifera varieties, 210 rootstocks and 720 hybrids originating from 47 countries). The INRA is not the owner of the land and the lease is expiring. This situation forces the INRA to move this vast collection. In complement of the conservatories, genetic resources could be preserved in private wine producing estates. Without questioning institutional clonal selection, which has shown its effectiveness, it is desirable to promote private mass selections on a minority but significant proportion of planted surfaces, for example 5\% [8]. Such a proportion would make possible to preserve a genetic diversity on approximately 40,000 ha in France, that is to say about 1000 times more what is possible today in the institutional conservatories.

The private clonal selections can also contribute, in a more limited way, to the preservation of the biodiversity. It is necessary to accompany these private selections (mass or clonal) in particular to limit the risk of propagation of virus diseases and phytoplasma. Mass selection is the easiest way to carry out a private selection of plant material. It is also possible to implement a true private clonal selection programme. This way requires obviously more important technical and financial means than the mass selection and contributes more modestly to the preservation of the biodiversity. 
From which vineyards private selection can be carried out?

Only vineyards which are not planted with clonal material are of interest for selection. That means most of the time old plots, planted before the generalization clonal material during 1970's. The majority of the vineyards planted before 1970 and all vineyards planted before 1960 meet this criterion. These plots will soon be pulled up, which makes urgent the need to save their genetic resources. It is particularly interesting to practise selections in vineyards which have a high quality potential for wine making. During operations of selection, all the virus infected vines will be eliminated. It is thus preferable to avoid selections in strongly contaminated plots because a strong rejection rate increases the cost of the selection.

\section{Difference between a mass selection and a private clonal selection}

Most of selection of plant material starts with an attentive observation of the candidate plot. The wine grower must fix his own criteria of selection: morphology of bunches, yield, berry size.... For some varieties, like the Cabernet franc, it can be interesting to select loose bunches with small berries. Indeed the genotypes with large compact bunches, are more sensitive to overproduction and grey rot. Once the plot chosen, vines that meet the selection criteria are marked. The best time to carry out the observations is the week which precedes harvest. The first year it is necessary to mark a great number of vines, several hundreds in a plot. The second year all the marked vines are visited and only the ones that meet the selection criteria again are preserved. The marks are removed from the vines that do not meet the selection criteria any more. The third year this operation is repeated. All the vines which still have their marks after the third year answered favorably to the selection during the three consecutive years. At this stage, ELISA tests will be carried out to check the absence of the principal viruses: Grapevine FanLeaf Virus (GFLV), Arabis Mosaic Virus (ArMV) and Grapevine Leaf Roll Virus (GLRaV) serotypes 1 and 3. Cuttings are sent next winter to a nursery, where they are grafted on the rootstock requested by the wine grower.

In the case of the traditional mass selection, there is generally no, or little, traceability between the mother stocks (generally several hundreds) and the produced vines: buds are multiplied in mass. It is possible however, and it can be recommended, to plant blocks resulting from mass selection with repetitions of rows of plants originating from each mother vine. Such a device makes possible to carry out if necessary in a second time selections leading to a private clonal selection [9].

For private clone selection, the choice of the mother vines is more restrictive and a maximum of few dozens of mother vines are selected. In addition, a total traceability is respected during grafting, which makes it possible to link each vine to its mother plant. The young vines produced are installed in a trial divided into blocks. All the numbers (potential clones) are present in each block, for example 5 stocks of each number in each block. Once the vines enter production, it becomes possible to make measurements on each number with replicates, in order to be able to carry out statistics on the results of measurements and observations. Many measurements are relatively easy to implement: grape yield per vine, bunch weight, fertility, berry weight, sugar content of the grape, total acidity or the rate of Botrytis cinerea at harvest.

After at least three years of measurements and observations in the trial plot, which contains several dozens of potential clones, it becomes possible to identify some clones which answer perfectly to the criteria of the vineyard manager and which can be multiplied. At this stage it becomes interesting to carry out micro vinifications to check the organoleptic characteristics of wines made from the pre-selected clones. A clone present in the trial block (a few dozens of individuals) will provide enough buds to make several hundreds of vines. At this stage it is not possible to plant whole blocks with only one clone resulting from the private clonal selection. In the first time, a block should be planted with several selected clones. From this block, buds can be used to produce new vines. However, these blocks should be regularly tested to make sure that the vines remain virus free. After a few years the estate can plant the clones they have selected and which are adapted to their Terroir and type of production. A private clonal selection is a process which is not difficult to carry out, but requires rigour and long-term vision, because the clones are produced after 12 years or more.

\section{Cost of mass or clonal private selection}

Traditional mass selection requires about five days of highly qualified work (1,000 €/day). The cost of serological tests (ELISA) is on average 6,000 €. For planting a plot with a density of 5,000 vines/ha, the additional cost of the plants is about $2,500 €$ (Table 1). The additional cost of mass selection is about $13,500 €$ for a one hectare plot. This investment may seem high for the first hectare planted. However, the estate can multiply this plant material on much larger plots and so obtain a return on investment. Mass selection should be considered as an initial investment, the cost decreasing with the area planted over the years. A private clonal selection requires 23 days of highly qualified work. The cost of the ELISA tests is $3,000 €$. For 25 clones tested, microvinifications could be carried out on the 10 clones considered a priori to be the most promising. They represent a total of $€ 30,000$ for three years of microvinifications. Chemical analysis can be carried out for $€ 2,000 /$ year approximately. The additional cost of manufacturing plants is identical to mass selection. It is about $€ 2,500$ in total. The additional cost of a private clonal selection is around $€ 65,000$ minimum for 23 working days (Table 1). This partly explains the fact that only prestigious properties are investing in private clonal selection. As for mass selection, the amount of that investment decreases with the area planted over the years.

\section{II) Methodology to study intravarietal diversity (example of the Portuguese approach)}

\section{Some materials and methods}

The selection strategy in Portugal is exemplified through the conservation/selection of the ancient Portuguese 
Table 1. Supplementary cost of private mass and clonal selections compared to a regular plantation for one hectare planted at 5,000 vines/ha.

\begin{tabular}{|c|c|c|}
\hline Mass selection & Stage & Clonal selection \\
\hline 3 days/ha & Selection in mother plot & 3 days/ha \\
\hline 2 days, 400 tests & $\begin{array}{l}\text { ELISA Tests: } 3,000 €(\text { Clonal Selection) } 6,000 € \text { (Mass } \\
\text { Selection) }\end{array}$ & 1 day, 200 tests \\
\hline $2,500 €$ & $\begin{array}{l}\text { Production of plants for field trial } \\
\text { Supplement of } 0.50 € / \text { vine }\end{array}$ & $500 €$ \\
\hline \multirow[t]{8}{*}{$\begin{array}{l}\text { Plantation and } \\
\text { production costs of a } \\
\text { classic young plot ( } 1 \mathrm{ha} \text { ) }\end{array}$} & $\begin{array}{l}\text { Plantation of the study trial (first three years) or production } \\
\text { plot }\end{array}$ & $\begin{array}{l}\text { Plantation and } \\
\text { production costs of a } \\
\text { classic young plot } \\
(0.20 \mathrm{ha})\end{array}$ \\
\hline & Field trial monitoring & 12 days \\
\hline & Data analysis 1day/year during 3 years & 3 days \\
\hline & Replantation of dead vines in the field trial & 3 days \\
\hline & $\begin{array}{l}\text { Micro-vinifications }(1,000 € * 3 \text { years } * 10 \text { most promising } \\
\text { clones) }\end{array}$ & $>30,000 €$ \\
\hline & Sensory analysis of wines produced by micro vinification & 1 day \\
\hline & Must and wine analyses & $6,000 €$ \\
\hline & Supplementary cost for the production of vines: $0.50 € /$ vine & $2,000 €$ \\
\hline$>13,500 €(5$ days $)$ & Supplementary cost compared to a regular plantation & $>65,000 €(23$ days $)$ \\
\hline
\end{tabular}

variety "Arinto". "Arinto" is one of white varieties with the strongest identity and largely cultivated in Portugal. "Arinto" genotypes were sampled in 4 Portuguese regions (Vinhos Verdes, Bairrada, Lafões and Bucelas). Subsequently, diagnosis of virus with highest frequency in Portugal (GLRaV3) was performed and positive genotypes for this virus were eliminated. Entering cycle 2 of the selection methodology, a large field trial was planted. It was located in the Setúbal wine region and laid out in a randomised complete block design with 247 genotypes (63 from Vinhos Verdes, 59 from Bairrada, 67 from Lafões and 58 from Bucelas), 4 plants per replicate and 4 complete blocks. Traits considered in this study were yield (kg/vine) in 1995, 1998, 1999 and 2000, soluble solids in the must ( ${ }^{\circ}$ Brix) and acidity (expressed in tartaric acid, g/L) in 2005 and 2006.

Data analysis was based on average yield values observed over several years and performed using PROC MIXED of SAS version 9.2 [10]. Mixed models were fitted to yield and quality traits data $[11,12]$. The parameters involved in the model were estimated by residual maximum likelihood (REML). A residual likelihood ratio test was used to test the null hypothesis that genotypic variance component was equal to zero. The p-value of the test was half of reported p-value from the chisquare distribution with one degree of freedom [13, 14]. Additionally, a generalized measure of broad-sense heritability was computed [15], in order to assess the amount of genetic information present in the data and, thus, evaluate selection efficiency. For better comparison of genetic variability among traits, coefficient of genotypic variation (ratio between the estimate of the genotypic standard deviation and the estimate of the mean of the population) was computed. With residual maximum likelihood estimates, the empirical best linear unbiased predictors (EBLUPs) of genotypic effects were obtained for each trait by solving the mixed model equations [16]. The EBLUPS of the genotypic effects were used to select different sets of clones (mass selection, polyclonal material). Four types of polyclonal material were obtained according to the following criteria:

Type 1 - The twenty top ranked clones for yield;

Type 2 - The twenty top ranked clones for soluble solids; Type 3 - The twenty top ranked clones for acidity;

Type 4 - A group of twenty clones composed by the five top ranked clones in yield, the ten top ranked in soluble solids and the 5 top ranked in acidity.

For each trait, prediction of genetic gain was computed as the average of EBLUPs of genotypic effects regarding selected genotypes. To better interpret results, predicted genetic gain was expressed as a percentage of the overall mean.

\section{Some results and discussion}

For the study conducted with the Portuguese methodology, results concerning quantification of genetic variability and selection are presented in Tables 2 and 3, respectively. Heritability values obtained for all traits were highly satisfactory (equal or greater than 0.85 ) meaning that a large portion of the total variability is due to genotypic effects (Table 2). It was also found that genetic variability of yield, ${ }^{\circ}$ Brix and acidity was significant (p-value $<0.05$ ). Presence of high genetic variability and high values for heritability for these three traits are good indicators for selection success. Among traits, genetic variability was higher for yield (higher value for coefficient of genotypic variation) which certainly will have consequences in genetic gains to be obtained by selection.

Results concerning polyclonal selection (Table 3) show that it is possible to select a group of superior clones concerning one or several traits with high genetic gains. Among the different types of polyclonal material obtained, in type 4, positive genetic gains for all traits were reached. For other types (1 and 2), gains in both 
Table 2. Estimates for genetic parameters and results for quantification of genetic variability for several traits of Portuguese variety "Arinto" [11]. $\hat{\mu}$ - overall mean, $\hat{\sigma}_{g}^{2}$ - genotypic variance estimate, $\hat{h}_{g}^{2}-$ generalized broad-sense heritability, $\mathrm{CV}_{\mathrm{G}}-$ coefficient of genotypic variation.

\begin{tabular}{lrccc}
\hline Trait & $\hat{\mu}$ & $\hat{\sigma}_{g}^{2}(\mathrm{p}$-value $)$ & $\hat{h}_{g}^{2}$ & $\mathrm{CV}_{\mathrm{G}}(\%)$ \\
\hline Yield (kg/plant) & 1.45 & $0.1283(<0.0001)$ & 0.85 & 24.7 \\
Soluble solids ( ${ }^{\circ}$ Brix $)$ & 21.17 & $2.7497(<0.0001)$ & 0.89 & 7.8 \\
Total. acidity (tartaric acid, g/L) & 5.90 & $0.388 \quad(<0.0001)$ & 0.80 & 10.6 \\
\hline
\end{tabular}

Table 3. Performance of four types of polyclonal material selected.

\begin{tabular}{lrrr}
\hline Type of polyclonal material & \multicolumn{3}{c}{ Predicted genetic gain (\%) } \\
\cline { 2 - 4 } & Yield & Brix & Acidity \\
\hline Type 1 & 36.1 & 4.9 & -5.5 \\
Type 2 & 17.7 & 11.0 & -7.4 \\
Type 3 & -25.5 & -12.5 & 21.3 \\
Type 4 & 10.9 & 3.0 & 1.7 \\
\hline
\end{tabular}

yield and soluble solids were obtained. Only with type 3 genetic gain for acidity resulted in losses for yield and soluble solids. These different materials should be used according to grape-growers objectives, but many other types of polyclonal material could be selected. However, it is important to emphasize that this is only possible because the work is based on a representative sample of overall genetic variability within the variety. Additionally, another important advantage of using polyclonal material is related to its environmental stability (low sensitivity to genotype by environment interaction).

\section{III) General conclusions}

The institutional clonal selection has the advantage of limiting the impact of virus diseases in plant material for vineyards. It presents also drawbacks, mainly the extreme erosion of genetic resources. An interesting way to maintain genetic diversity in the vineyard is to promote other ways of selection, like the mass selection and the private clonal selection, on significant surfaces like $5 \%$ of the total area planted with vines in a given winegrowing region. These ways of alternative selections represent a significant cost for those who implement it. By considering that they take part in the preservation of general genetic diversity, and thus deliver a service to the community, it would not be aberrant to imagine government aid, in particular in the form of free technical support. This support would also provide frame to the alternative forms of grapevine selection and to prevent dissemination of virus diseases. Mass and private clonal selection require also a good organization of the producers implementing this strategy. Mass selection requires 3 to 4 years of anticipation and private clonal selection more than 12 years.

According to the methodology developed in Portugal, it is possible to conserve and exploit genetic variability within an ancient variety through the selection of several types of polyclonal material adapted to objectives of winegrowers. These different mass selections provide high genetic gains (and corresponding economic gains) and also preserve diversity on-farm. A complementary way of ex-situ conservation is represented by the large field trial of the second cycle of Portuguese selection methodology.

The methodologies to solve the serious problem of the erosion of intravarietal diversity within ancient grapevine varieties are available, what is missing is to build consensus and create legislative contexts that favor their widespread application.

We are grateful to the colleagues of "Portuguese National Network for Grapevine Selection" for their help in management of field experiments and data collection.

\section{References}

[1] T. Lacombe, J.-M. Boursiquot, L. Audeguin. Prospection, conservation et évaluation des clones de vigne en France. Bull. OIV, 77, 799-809 (2004)

[2] D. Forget, M.C. Dufour, T. Lusseau. Bilan et perspectives pour la sélection clonale des principaux cépages du Bordelais. Prog. Agric. Vitic., 119, 199206 (2002)

[3] van Leeuwen C., Roby J.-P., Alonso-Villaverde V. and Gindro K. (2013). Impact of clonal variability in Vitis vinifera Cabernet franc on grape composition, wine quality, leaf blade stilbene content and downy mildew resistance. J. Agric. Food Chem., 61, 19-24

[4] Martins, A.; Carneiro, L. \& Castro, R. (1990). Progress in mass and clonal selection of grapevine varieties in Portugal. Vitis, special issue, pp. 485489, ISSN 0042-7500

[5] Martins, A. (2009). Genetic diversity of portuguese grapevines: methods and strategies for its conservation evaluation and conservation. Acenología, No. 112, Available from http://www . acenologia.com/cienciaytecnol ogia/variedades_portuguesas_cien1209.htm

[6] E. Gonçalves, A. St. Aubyn, A. Martins. Heredity, 104, 6 (2010)

[7] L. Audeguin, R. Boidron, P. Bloy, S. Grenan, P. Leclair, J.-M. Boursiquot. L'expérimentation des clones de vigne en France. Etat des lieux, méthodologie et perspectives. Revue Française d'Enologie, 184, 8-11 (2000)

[8] C. van Leeuwen et J.-P. Roby. Diversité génétique de la vigne: promouvoir plusieurs voies de sélection. Union Girondine, 1063, 38-44 (2010)

[9] C. van Leeuwen et J.-P. Roby. Préservation des ressources génétiques de la vigne. Cohabitation entre sélection clonale institutionnelle, sélection massale 
et sélection clonale privée. Revue des œnologues, 148 (2013)

[10] SAS Institute Inc. (2008). SAS/STAT ${ }^{\circledR} 9.2$ User's Guide. SAS Institute Inc., ISBN 978-1-59047-949-0, Cary, NC, USA

[11] E. Gonçalves, A. Martins. Genetic variability within varieties: the basis for selection and for innovation. Proceedings of the 34th World Congress of Vine and Wine (OIV, Porto, 2011)

[12] E. Gonçalves, A. St. Aubyn, A. Martins. Theor. Appl. Genet. 115, 5 (2007)
[13] Self, S. \& Liang, K. (1987). Asymptotic properties of maximum likelihood estimators and likelihood ratio tests under nonstandard conditions. J Am Stat Assoc, Vol.82, No.398, pp. 605-610, ISSN 0162-1459

[14] Stram, D. \& Lee, J. (1994). Variance components testing in the longitudinal mixed effects model. Biometrics, Vol. 50, No.4, pp. 1171-1177, ISSN 1541-0420

[15] E. Gonçalves, I. Carrasquinho, A. St. Aubyn, A. Martins. Euphytica, 189, 3 (2013)

[16] C. Henderson. Biometrics, 31, 2 (1975) 